\title{
Interspecific xenia and metaxenia in seeds and fruits of tomato
}

\author{
Fernando Angelo Piotto ${ }^{1}$, Katherine Derlene Batagin-Piotto², Marcílio de Almeida², Giancarlo Conde Xavier Oliveira ${ }^{1}$ *
}

1USP/ESALQ - Depto. de Genética, Av. Pádua Dias, 11, C.P. 83 - 13400-970 - Piracicaba, SP - Brasil.

2USP/ESALQ - Depto. de Ciências Biológicas, Av. Pádua

Dias, 11, C.P. 9 - 13418-900 - Piracicaba, SP - Brasil.

*Corresponding author <gcxolive@usp.br>

Edited by: Leonardo Oliveira Medici

Received January 19, 2012

Accepted September 05, 2012
ABSTRACT: Xenia, the transmission of traits from the pollinizer to the female's tissues, is a phenomenon hitherto unknown in tomatoes. Here, we describe xenia effects on the seeds and fruits of Solanum lycopersicum, the tomato, elicited by S. galapagense. The wild tomatoes, such as $S$. galapagense, have highly pilose fruit surface and minute seeds, unlike the domesticated species. Crossings between S. galapagense (pollinizer) and two large-seeded, glabrous cultivars of $S$. lycopersicum (females) tested the former's ability to raise the trichome density and trichome-to-1000-cell ratio and to reduce the seed weight in the latter's fruits. Selfed fruits of the two cultivars, Micro-Tom and Pusa Ruby, were compared to the crossed fruits. The pollen of $S$. galapagense was able to raise pilosity and to reduce seed weight in the crossed fruits of both cultivars, but with different magnitudes: seed reduction was more intense in Pusa Ruby, while pilosity increase was greater in Micro-Tom, both of which characterize xenia. Pilosity increase is not completely dependent on variation in epidermal cell density, which displayed no xenia effect. The difference between the maternal cultivars in the magnitude of pilosity increase may be due to the higher dilution of a putative male chemical signal (either hormone or RNA) in the larger fruits of Pusa Ruby. However, one cannot use the signal diffusion hypothesis to explain the xenia effects on seed weight.

Keywords: hormones, pollination, microscopy, wild relative

\section{Introduction}

Xenia, a term coined by Focke (1881), is "the direct or indirect effect of the male gamete on tissues other than embryonic ones" (Denney, 1992, after modifying Sinnott and Dunn, 1939). The term encompasses "metaxenia", the specific case of xenia occurring only in the maternal tissue (Swingle, 1928), triggered by a signal from the tissues bearing paternal genes. It has been observed since ancient times and is connected to the rediscovery of Mendelism itself through Correns' studies on xenia in peas in the 1890's (Rheinberger, 2000).

Xenia/metaxenia has been mainly proposed for improving maize yield (Weingartner et al., 2002) and several fruit crops, such as pecan nuts, pistachio nuts and avocado (Robbertse et al., 1996; Sedgley and Griffin, 1989), but especially date palms (Nixon, 1928; Shaheen et al., 1989). In contrast, no instance of this phenomenon has ever been described in tomatoes (Solanum lycopersicum L.).

In the early tomato fruit, trichomes grow from the epidermal layer, but they disappear or become rare in the mature fruit (Atherton and Rudich, 1986). In contrast, the trichomes of $S$. galapagense are abundant and permanent. Generally, the more seeds, the larger the fruit tends to be in tomato (Dogterom et al., 1998), but the seed stimulus can be replaced by either hormones or pollination by a wild species (Picken, 1984). Pollination induces MADS-box genes to control epidermis cell density (ECD) and pericarp size in the first week after anthesis (Atherton and Rudich, 1986; Gillaspie et al., 1993; Busi et al., 2003).

This study aims at describing xenia in seed weight and metaxenia in ECD and trichome density on the to- mato fruit after pollination by $S$. galapagense S. Darwin and Peralta. We also tested the hypotheses that (i) the magnitude of metaxenia for trichome density is not dependent simply on the variation in ECD and that (ii) fruit volume of the female plant influences the degree of metaxenia effect.

\section{Materials and Methods}

Solanum galapagense S. Darwin and Peralta, described as a new species in Darwin et al. (2003), and S. lycopersicum L., the cultivated tomato, are self-compatible, autogamous species belonging to the section Lycopersicon, together with other 13 species, which are collectively called tomatoes (Spooner et al., 2005). S. galapagense, commonly known as tomatillo or Galápagos tomato, is a perennial herb endemic to the Galápagos Islands, mostly occurring on coastal lava in the western and southern islands of the archipelago. The stem, leaves, petioles and calyx are pubescent. The fruits are normally glabrescent to densely pubescent. The particular genotype used here (accession LA 1401, Tomato Genetics Research Center [TGRC], Davis, California) has fruits much more pubescent than those of $S$. lycopersicum (Figure 1B-C). S. galapagense has small seeds (ca. $2 \times 1 \mathrm{~mm}$; Darwin et al., 2003) as compared to $S$. lycopersicum (Rick, 1983). Two cultivars of $S$. lycopersicum were used, viz., cultivar Micro-Tom (MT), a dwarf variety with three loci fixed for alleles determining small height (Meissner et al., 1997), which has also small fruits (fruit weight $=7.1 \pm 0.28 \mathrm{~g}$ ), and the cultivar Pusa Ruby (PR), with normal height and fruit size (fruit weight $=46.62 \pm 2.97 \mathrm{~g}$ ).

We crossed plants grown in individual pots of 10 $\mathrm{L}$, containing a mixture, in equal parts, of commercial 
substrate and vermiculite, placed in a greenhouse in $\mathrm{Pi}$ racicaba, state of São Paulo, Brazil, during Feb-May of $2009\left(23.34 \pm 2.27^{\circ} \mathrm{C}\right)$, in a random design. One supplied nutrition weekly with Hoagland and Arnon (1950) solution. One plant of $S$. galapagense was always the pollen donor, or pollinizer, and five plants of each variety of $S$. lycopersicum were the female parents in all crossings. In each female plant, we utilized four flowers located in the same raceme (second raceme of the first sympod) in the experiments, and removed the others: we crosspollinated two flowers by hand with tweezers (Stevens and Rick, 1986) and let two flowers to be naturally selfed to serve as controls. After the beginning of fruit development, we left only one cross-pollinated flower and one selfed flower per raceme, and removed the other two

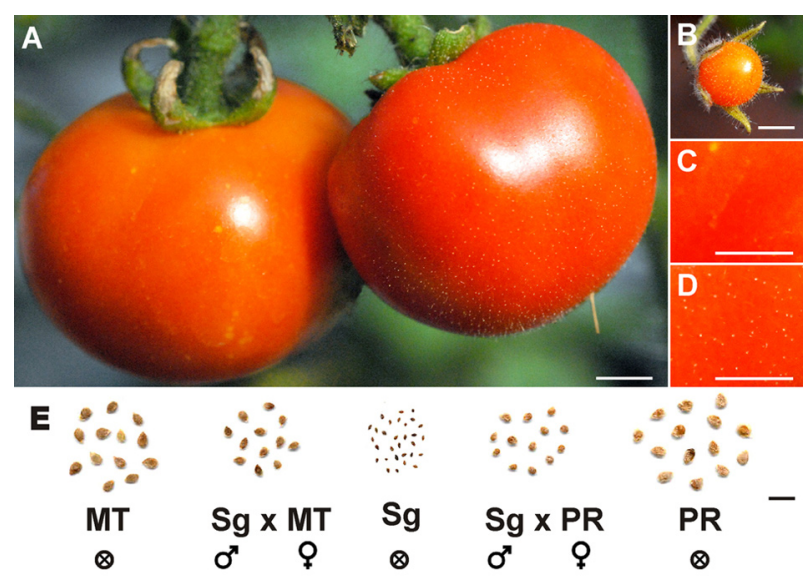

Figure 1 - Effect of Solanum galapagense (Sg) pollen on trichome density of cultivar Micro-Tom (MT) and on seed weight of both cultivar MT and cultivar Pusa Ruby (PR). (A) increase of trichome number in fruits of cultivar MT pollinated by $S$. galapagense (left) compared with fruits of the same plant obtained by selfing (right); (B) fruit of S. galapagense showing a high trichome density; (C) epidermis of selfed MT fruit showing low trichome density; (D) epidermis of MT fruit developed after pollination by S. galapagense; (E) reduction in seed size of cultivar MT and cultivar PR following pollination by $S$. galapagense $(\mathrm{Sg} \times \mathrm{MT}$ and $\mathrm{Sg} \times \mathrm{PR})$. MT, $\mathrm{Sg}$ and PR are selfed seeds. Bar $=5 \mathrm{~mm}$. flowers. Thus, we studied five types of fruit (treatments): MT (selfed Micro-Tom); PR (selfed Pusa Ruby); Sg (selfed S. galapagense); Sg $\times$ MT (Micro-Tom pollinated by $S$. galapagense) and $\mathrm{Sg} \times \mathrm{PR}$ (Pusa Ruby pollinated by $S$. galapagense). In preliminary studies on the phenomenon described, we noticed that it does not vary with the climatic conditions, season or other environmental factors, the heritability of the trait seeming to be very high.

We assessed three characters: trichome density, epidermal cell density and seed weight. Trichomes and cells were counted in completely mature fruits by pressing the fruit against a drop of cyanoacrylate ester spread over a glass slide, and by keeping it in that position for 8 seconds, until the polymerization of the adhesive was complete. The fruit was removed from the thin, transparent film attached to the slide. The epidermal impression left in the film revealed the cells and several types of trichomes under ordinary light microscopy and a digital camera captured the images at the same scale. The count included all the types of trichome. Trichome and cell density were estimated by counting the number of trichomes and cells within a $1-\mathrm{mm}^{2}$ square imprinted on a special ocular lens. We took epidermal impressions from three faces on the middle lateral portion of each fruit and averaged the three-subsample values for each character obtained from them to produce one repeat. Thus, there were five repeats per maternal variety per character. We estimated the number of trichomes per 1,000 epidermal cells (the trichome-to-1,000-cell ratio) using the trichome and cell density data.

For the seed weight measures, we bulked all the fruits of a given treatment, extracted the seeds, divided them into 10-seed samples, and weighed, considering each 10-seed sample as a repeat. Since the treatments differed in their total number of seeds, the number of repeats also varied: 16 (MT), $15(\mathrm{PR}), 15$ (Sg), 9 (Sg × $\mathrm{MT})$ and $16(\mathrm{Sg} \times \mathrm{PR})$.

For all the statistical analyses of cell density, trichome density and seed weight variation, the $\mathrm{R}$ software version 2.13.2 was used ( $\mathrm{R}$ Development Core Team, 2009). Seed data were transformed with $\mathrm{x}^{\mathrm{n}}$, where $n=0.173925$, obtained by the Boxcox function in MASS $\mathrm{R}$ package. A multiple comparison between means by the Duncan test followed an individual Analysis of Variation for each character, at a 0.05 level of significance.

Table 1 - Variation in seed weight and epidermal micromorphology in the fruits of Solanum lycopersicum varieties and the wild species $S$. galapagense. MT and PR are the S. Iycopersicum varieties Micro-Tom and Pusa Ruby, respectively. Sg is the wild species S. galapagense. The fruits in MT, PR and Sg were selfed and those in Sg $\times$ MT and Sg $\times$ PR were obtained by using Sg as the pollen donor in crossings with MT and PR. Complete xenia cases are in bold and partial xenia cases are underlined.

\begin{tabular}{|c|c|c|c|c|}
\hline & Trichome density & Cell density & Ratio & Seed weight \\
\hline & \multicolumn{2}{|c|}{ number $\mathrm{mm}^{-2}$} & trichome to 1000 cells & $\mathrm{mg}$ \\
\hline MT & $5.73 \pm 0.13 c$ & $945.54 \pm 53.52 \mathrm{a}$ & $6.15 \pm 0.40 c$ & $23.86 \pm 0.52 b$ \\
\hline $\mathrm{Sg} \times \mathrm{MT}$ & $12.70 \pm 0.83 a$ & $990.00 \pm 60.46 \mathrm{a}$ & $13.11 \pm 1.30 \mathrm{a}$ & $\underline{13.94 \pm 0.30 \mathrm{c}}$ \\
\hline Sg & $14.23 \pm 0.79 a$ & $1031.50 \pm 34.63 a$ & $13.92 \pm 1.14 \mathrm{a}$ & $1.36 \pm 0.03 \mathrm{e}$ \\
\hline $\mathrm{Sg} \times \mathrm{PR}$ & $8.25 \pm 0.22 b$ & $625.42 \pm 23.62 b$ & $13.31 \pm 0.81 \mathrm{a}$ & $\underline{11.09 \pm 0.22 \mathrm{~d}}$ \\
\hline PR & $5.27 \pm 0.36 c$ & $527.60 \pm 15.96 b$ & $10.06 \pm 0.87 b$ & $29.26 \pm 0.34 \mathrm{a}$ \\
\hline
\end{tabular}

Different letters indicate the means are different at $p<0.05$. 


\section{Results}

There was variation in trichome density $\left(\mathrm{F}_{4,20}=\right.$ $54.89, p<0.001$; Table 1). The Sg mean was not different from the $(\mathrm{Sg} \times \mathrm{MT})$ mean and both were higher than the MT mean; the Sg mean was different from both the PR mean and their crossing product $(\mathrm{Sg} \times \mathrm{PR})$ mean, which was intermediate. Differences in cell density were also found $\left(\mathrm{F}_{4,20}=31.16, p<0.001\right.$; Table 1$)$. The means of $\mathrm{MT}, \mathrm{Sg} \times \mathrm{MT}$ and Sg were not different from each other, but were different from $\mathrm{PR}$ and $\mathrm{Sg} \times \mathrm{PR}$.

The trichome-to-1,000-cell ratios were different among treatments $\left(\mathrm{F}_{4,20}=11.59, p<0.001\right.$; Table 1). The means $\mathrm{Sg}, \mathrm{Sg} \times \mathrm{MT}$, and $\mathrm{Sg} \times \mathrm{PR}$ were not different among themselves, but they were different from both MT and PR, which were also different from each other. All the seed weight means were strongly different among themselves $\left(\mathrm{F}_{466}=4,800.9, p<0.001\right.$; for the Duncan test, $p<0.05)$. Sg fruits had the lightest seeds, and the fruits originated by crossing had seed weight means intermediate between the Sg mean and their respective female parent means (Figure $1 \mathrm{E})$. The $(\mathrm{Sg} \times$ MT) mean was between the MT mean and the Sg mean; similarly, the $(\mathrm{Sg} \times \mathrm{PR})$ mean was between the PR mean and the Sg mean.

\section{Discussion}

The pollen of $S$. galapagense used to fertilize $S$. lycopersicum plants is able to affect the phenotype of seeds and fruits directly developed from the pollinated flowers, that is, these characters can present xenia (metaxenia in the case of fruits, more precisely). Some of the specific character states present in $S$. galapagense, viz., high trichome density and small seed size, are transferred to the fruits and endosperm, respectively, of the contrasting pollinated plant. The magnitude of this influence, however, varies with the character and with the maternal cultivar. In both types of cross, the trichome density of the pollinated fruits shows an increase in comparison to the selfed fruits, which represent the normal type of the female varieties and, actually, of S. lycopersicum varieties in general.

The increase in the mean is more pronounced, though, in the cross-pollinated fruits produced by MicroTom females (Figure 1A), whose mean is indistinguishable from the father's. In this case, the phenomenon can be described as complete interspecific metaxenia. Conversely, in the crosses between $S$. galapagense and Pusa Ruby, the mean of the crossed fruits is intermediate in relation to the means of the parents, which characterizes partial interspecific metaxenia for trichome density. The explanation for this difference between the metaxenia effects on each cultivar may rest on the difference in fruit size, assuming that the effect depends on the diffusion of one or more signaling substances across the fruit, as some authors believe (Perazza, 1998; Swingle, 1928), and that the pollen tube and/or the male nuclei produce always the same amount of signal.

Size variation in tomato fruits can be explained at the morphological level largely by differences in the number of carpels (or locules) or in cell number or size (Frary et al., 2000). Whatever the underlying reason, cultivar Pusa Ruby is considerably larger than cultivar Micro-Tom, which would cause the signal to be diluted, and consequently the magnitude of metaxenia to be lesser in the former, where the minimal dose for complete effect would not be reached. On the other hand, there was no metaxenia effect in cell density. Actually, as it turned out only after data collecting, cultivar Micro-Tom revealed not to be the ideal material for testing metaxenia in crosses with $S$. galapagense, because cell densities in both species are indistinguishable and any potential influence of the wild pollen would be undetectable (Table 1). Conversely, cultivar Pusa Ruby and S. galapagense do present a difference in epidermal cell density, allowing metaxenia to be tested, but the wild pollen was unable to raise the values of the character in the cross-pollinated fruits (Table 1).

Cultivar Pusa Ruby has fewer cells per $\mathrm{mm}^{2}$ and consequently larger cells, which may be one of the mechanisms whereby the total fruit size is increased in this cultivar as contrasted to cultivar Micro-Tom and $S$. galapagense, both the same size (Table 1), assuming that the sizes of all cell types in the fruit are positively correlated. However, if we assume that trichomes are a specialized type of epidermal cell, we can expect that an increase in epidermal cell density would provoke a proportional increase in the trichome density. Such an expectation could serve as a null hypothesis for testing the real effect of pollen. A simultaneous analysis of the three first columns in Table 1 shows that (i) Sg pollen does not increase MT cell density. But even so, roughly doubles MT trichome density (from 5.73 to 12.70), consequently doubling the value of the variable trichome-to-1000-cell ratio (from 6.15 to 13.11); (ii) Sg pollen provokes a disproportionately greater increase in PR trichome density $(56.6 \%)$ than in PR cell density $(18.5 \%)$, which is reflected in an increase of ca. $32 \%$ in the trichome-to-1,000-cell ratio. Thus, we can reject the null hypothesis of directly proportional dependence of trichome density on cell density at $p<0.001$. The null hypothesis would be corroborated if the trichometo-1,000-cell ratios of the cross-pollinated fruits and of their maternal parents were similar, but they are not. We can thus consider as provisionally plausible the idea that Sg pollen promotes the increase in trichome density by supplementary, unknown mechanisms.

The weight of $S$. galapagense seeds is between ca. 17 and 21 times lesser than that of Micro-Tom and Pusa Ruby, so the character is particularly adequate for testing xenia. We observed a clear-cut partial xenia effect in both pollen-receptor cultivars. Sg pollen provoked a more pronounced reduction in seed weight in the cultivar with larger seeds (62.1\% in Pusa Ruby against 41.6 
$\%$ in Micro-Tom; Figure 1E), which cannot be explained by the diffusion of a signal through the volume of the seeds. Further investigation is needed to clarify the mechanism underlying seed weight xenia.

We detected for the first time the occurrence of both endospermic xenia and metaxenia in tomatoes $(S$. lycopersicum). As with the occurrence of metaxenia in Hylocereus polyrhizus (Mizrahi et al., 2004), the phenomenon was elicited by pollen of a different species (interspecific xenia). The hairy-fruited, small-seeded species $S$. galapagense was able to transmit these traits to the fruits immediately developed from the flowers it pollinated. Transmission was partial in some instances and practically complete in others.

Some characters that have been shown to be affected by the xenia effect in other species are also related to seed size, indicating that the phenomenon is not rare. Among these cases are seed size in Vicia faba L. (Duc et al., 2001), seed and embryo size in Gossypium hirsutum L. (Pahlavani and Abolhasani, 2006), grain weight and grain yield in Zea mays (Liu et al., 2010), nut size and yield in Macadamia integrifolia Meiden and Betche and Macadamia tetraphylla L.A.S. Johnson (Trueman and Turnbull, 1994). Most cases of xenia in seeds reported in crop plants involve quantitative traits, as those studied here in tomato, but some show qualitative variation, as seed coat in pumpkins (Cheng et al., 2002). In other cases, the effects are in chemical contents, not weight: endosperm composition and enzymatic activity in Zea mays L. (Bulant et al., 2000), oil and fatty acid content in Prunus amygdalus Batsch (Kodad et al., 2009). Cases of metaxenia are also reported, as father-controlled changes in fruit weight in mandarins (Wallace and Lee, 1999), but, to our knowledge, no case involving fruit pilosity has been described to allow comparison with the trichome growth shown here.

Interspecific xenia effects, as those shown here by tomatoes, have been reported less frequently than intraspecific xenia. The differential alteration of ripening time in fruits of the cactus Hylocereus polyrhizus (F.A.C. Weber) Britton and Rose after pollination by Selenicereus grandiflorus (L.) Britt. and Rose and Selenicereus megalanthus (Schum.) Britt. and Rose (Mizrahi et al., 2004) is an example of interspecific metaxenia.

The precise cellular and biochemical mechanism underlying the interspecific xenia (including metaxenia) effect in tomato here reported remains to be investigated, but the results are compatible with some general hypotheses proposed to explain xenia at the molecular level (Liu, 2008). The first hypothesis assigns the mechanism of xenia to the action of hormones produced by the embryo or the endosperm (Swingle, 1928; Liu, 2008). Hormones produced by the seeds, mainly auxins, would be responsible for fruit growth and the number of seeds (and presumably their mass) would be positively correlated with fruit size (Dag and Mizrahi, 2005). However, this general and constant effect of hormones, independent of the male genotype, would not account for the much more specific male character states transmitted to fruits affected by xenia (Liu, 2008).

The hormonal hypothesis would not explain the lack of effect of the auxins on the embryos and the endosperm themselves, which produce them (Denney, 1992). Hormones, however, need specific receptors (mainly transmembrane proteins) in their target cells in order to trigger their effects in fruits, including tomatoes (Mounet et al., 2009). Such receptors are likely to be necessary in the tomato fruit cells for the xenia traits to be expressed, but they may not be expressed or active in the embryo and/or endosperm cells during fruit morphogenesis, which would explain why the hormone effect might not affect the embryo or the endosperm. The putative hormone produced by $\mathrm{Sg} \times \mathrm{MT}$ and $\mathrm{Sg} \times$ PR hybrid embryos or endosperm is probably also necessary for hair formation on the fruits of $S$. galapagense and finds the same tissue-specific receptors in the cells of $S$. lycopersicum cross-pollinated fruits. These fruits would respond to unusually high concentrations of hormone by producing hair densities and trichome-to-1000-cell ratios atypical of $S$. lycopersicum. As expected under this hypothesis, the xenia effect in the trichome traits was more intense on the smaller fruits of cultivar MT, where hormones could reach higher concentrations.

The second main hypothesis states that the signal to trigger the xenia effect may be mRNAs (Liu, 2008). In its original version, the mRNAs would be released by the pollen tube and diffuse out into the fruit and seed maternal tissues, but there would not be any logical impediment to assume an embryonic or endospermic origin to the molecules. In the last decade or so, many discoveries in molecular and cell biology showed that RNA molecules can be trafficked between cells and between different parts of the organism, both in animals and in plants. So-called exosomal shuttle RNA (esRNA) can be discharged in the microenvironment of animal cells by exosomes in a way similar to, but more efficient than, hormones (Valadi et al., 2007). In plants, RNAs can be transported from cell to cell through both plasmodesmata and the phloem (Voinnet, 2009; Kudo and Harada, 2007).

Although miRNAs (microRNAs) may have some role in cell-to-cell communication, the signaling action of mRNAs is more abundantly documented (Voinnet, 2009; Lough and Lucas, 2006). Phloemics, the integrated genomic, transcriptomic, proteomic and metabolomic analysis of phloem exudates has permitted the study of RNA profiles, which consist, in some species, of 1500 different mRNAs and thousands of small RNA types (Lough and Lucas, 2006). Both diffusion through plasmodesmata and the phloem could account for signal transmission within the tomato fruit and could thus be involved in the observed expression of xenia, providing a basis for Liu's hypothesis. The RNA molecules may originate either in the endosperm or the embryo, or even in the pollen tube, since mRNAs have been found also in sperm cells of plants (Engel et al., 2003). The effect 
of seed number on fruit growth (Dogterom et al., 1998) indicates the action of chemical signals produced by the seeds on the fruits and makes plausible the link between xenia and signals.

\section{Conclusions}

There are complete xenia effects in both MT and PR cultivars for the trichome-to-1000-cell ratio and only in MT for trichome density. Partial xenia effects were detected in PR for trichome density and in both MT and PR cultivars for seed weight. No xenia effect could be detected for the trait cell density in either cultivar. There is an influence of the maternal cultivar on the magnitude (in percentage of change) of xenia. Only the pattern of the alterations in trichome density and trichome-to-1000 -cell ratio provoked by foreign pollen is compatible with the diffusion hypothesis. According to this hypothesis, the magnitude of the xenia effect is controlled by a molecular signal (either hormone or RNA) produced by cells bearing male genes. This signal diffuses out through the fruit and becomes more diluted in larger fruits, which display a lesser phenotypic change.

\section{Acknowledgments}

The first author (FAP) received a fellowship of the Conselho Nacional de Desenvolvimento Científico e Tecnológico (CNPq), of the Ministério da Ciência e Tecnologia do Brasil. The second author (KDB-P) receives a fellowship of the Coordenação de Aperfeiçoamento de Pessoal de Nivel Superior (CAPES), of the Ministério da Educação do Brasil. The PROEX Program of CAPES supported this work. We thank Márcio de Castro Silva Filho and Ricardo Antunes de Azevedo, coordinators of ESALQ Graduate Program in Genetics and Plant Breeding and responsible for the PROEX Program, for financial support. We also thank Etienne Vernet, of the non-governmental organization "Kokopelli Seed Foundation", for kindly providing seeds of the "Pusa Ruby" cultivar.

\section{References}

Abd-Elsalam, K.A.; Omar, M.R.; Migueli, Q.; Nirenberg, H.I. Atherton, J.G.; Rudich, J. 1986. The tomato crop: a scientific basis for improvement. Chapman and Hall, London, UK.

Bulant, C.; Gallais, A.; Matthys-Rochon, E.; Prioul, J.L. 2000. Xenia effects in maize with normal endosperm. II. Kernel growth and enzyme activities during grain filling. Crop Science 40: 182-189.

Busi, M.V.; Bustamante, C.; D'Angelo, C.; Hidalgo-Cuevas, M.; Boggio, S.B.; Valle, E.M.; Zabaleta, E. 2003. MADS-box genes expressed during tomato seed and fruit development. Plant Molecular Biology 52: 801-815.

Cheng, Y.; Zhang, B.; Zhang, E.; Zhao, Z. 2002. Germplasm innovation by interspecific Crosses in pumpkin. Cucurbit Genetics Cooperative Report 25: 56-57.
Dag, A.; Mizrahi, Y. 2005. Effect of pollination method on fruit set and fruit characteristics in the vine cactus Selenicereus megalanthus ("yellow pitaya"). Journal of Horticultural Science and Biotechnology 80: 618-622.

Darwin, S.C.; Knapp, S.; Peralta, I.E. 2003. Taxonomy of tomatoes in the Galápagos Islands: native and introduced species of Solanum section Lycopersicon (Solanaceae). Systematics and Biodiversity 1: 29-53.

Denney, J.O. 1992. Xenia includes metaxenia. HortScience 27: 722-728.

Dogterom, M.H.; Matteoni, J.A.; Plowright, R.C. 1998. Pollination of greenhouse tomatoes by the North American Bombus vosnesenskii (Hymenoptera: Apidae). Journal of Economic Entomology 91: 71-75.

Duc, G.; Moessner, A.; Moussy, F.; Mousset-Déclas, C. 2001. A xenia effect on number and volume of cotyledon cells and on seed weight in faba bean (Vicia faba L.). Euphytica 117: 169-174.

Engel, M.L.; Chaboud, A.; Dumas, C.; Cormick, S.M. 2003. Sperm cells of Zea mays have a complex complement of mRNAs. The Plant Journal 34: 697-707.

Focke, W.O. 1881. The Plant Hybrids: a Contribution to the Biology of Growth. Borntraeger, Berlin, Germany (in German).

Frary, A.; Nesbitt, T.C.; Frary, A.; Grandillo, S.; Knaap, E.; Cong, B.; Liu, J.; Meller, J.; Elber, R.; Alpert, K.B.; Tanksley, S.D. 2000. fw2.2: a quantitative trait locus key to the evolution of tomato fruit size. Science 289: 85-88.

Gillaspie, G.; Ben-David, H.; Gruissen, W. 1993. Fruits: a developmental perspective. Plant Cell 5: 1439-1451.

Hoagland, D.R.; Aranon, D.I. 1950. The Water-Culture Method for Growing Plants Without Soil. University of California Agricultural Experimental Station, Berkeley, CA, USA.

Kodad, O.; Estopañán, G.; Juan, T.; Company, R.S. 2009. Xenia effects on oil content and fatty acid and tocopherol concentrations in autogamous almond cultivars. Journal of Agricultural and Food Chemistry 57: 10809-10813.

Kudo, H.; Harada, T. 2007. A graft-transmissible RNA from tomato rootstock changes leaf morphology of potato scion. Hortscience 42: 225-226.

Liu, Y.E.; Liu, P.; Dong, S.T.; Zhang, J.W. 2010. Hormonal changes caused by the xenia effect during grain filling of normal corn and high-oil corn crosses. Crop Science 50: 215-221.

Liu, Y.S. 2008. A novel mechanism for xenia? HortScience 43: 706. Lough, T.J.; Lucas, W.J. 2006. Integrative plant biology: role of phloem long-distance macromolecular trafficking. Annual Reviews of Plant Biology 57: 203-232.

Meissner, R.; Jacobson, Y.; Melamed, S.; Levyatuv, S.; Shalev, G.; Ashri, A.; Elkind, Y.; Levy, A. 1997. A new model system for tomato genetics. The Plant Journal 12: 1465-1472.

Mizrahi, Y.; Mouyal, J.; Nerd, A.; Sitrit, Y.; 2004. Metaxenia in the vine cacti Hylocereus polyrhizus and Selenicereus spp. Annals of Botany 93: 469-472.

Mounet, F.; Moing, A.; Garcia, V.; Petit, J.; Maucourt, M.; Deborde, C.; Bernillon, S.; Le Gall, G.; Colquhoun, I.; Defernez, M.; Giraudel, J.L.; Rolin, D.; Rothan, C.; Lemaire-Chamley, M. 2009. Gene and metabolite regulatory network analysis of early developing fruit tissues highlights new candidate genes for the control of tomato fruit composition and development. Plant Physiology 149: 1505-1528. 
Nixon, R. 1928. Immediate influence of pollen in determining the size and time of ripening of the fruit of the date palm. Journal of Heredity 19: 241-255.

Pahlavani, M.H.; Abolhasani, K. 2006. Xenia effect on seed and embryo size in cotton (Gossypium hirsutum L.). Journal of Applied Genetics 47: 331-335.

Perazza, D. 1998. Gibberellins promote trichome formation by up-regulating GLABROUS1 in Arabidopsis. Plant Physiology 117: 375-383.

Picken, A.J.F. 1984. A review of pollination and fruit set in the tomato (Lycopersicon esculentum Mill.) Journal of Horticultural Science 59: 1-13.

R Development Core Team. 2009. R: A Language and Environment for Statistical Computing. $\mathrm{R}$ Foundation for Statistical Computing. Vienna, Austria. Available at: www.r-project.org. Version 2.13.2 [Accessed Mar. 10, 2011]

Rheinberger, H.-J. 2000. Mendelian inheritance in Germany between 1900 and 1910: the case of Carl Correns (1864-1933). Comptes Rendues de l'Academie des Sciences de Paris 323: 1089-1096.

Rick, C.M. 1983. Genetic variability in tomato species. Plant Molecular Biology Reporter 1: 81-87.

Robbertse, P.J.; Coetzer, L.A.; Johannsmeier, M.F.; Swart, D.J. 1996. Hass yield and fruit size as influenced by pollination and pollen donor: a joint progress report. South African Avocado Growers' Association Yearbook 19: 63-67.

Sedgley, M.; Griffin, A.R. 1989. Sexual Reproduction in Tree Crops. Academic Press, London, UK.

Shaheen, M.A.; Bacha, M.A.; Nasr, T.A. 1989. Effect of male type on fruit chemical properties in some date palm cultivars. Annals of Agricultural Sciences 34: 265-281.
Sinnott, E.W.; Dunn, L.C. 1939. Principles of Genetics. McGrawHill, New York, NY, USA.

Spooner, D.M.; Peralta, I.E.; Knapp, S. 2005. Comparison of AFLPs with other markers for phylogenetic inference in wild tomatoes [Solanum L. Section Lycopersicon (Mill.) Wettst.]. Taxon 54: 43-61.

Stevens, M.A.; Rick, C.M. 1986. Genetics and breeding. p. 35-109. In: Atherton, J.G.; Rudich J., eds. The tomato crop: a scientific basis for improvement. Chapman and Hall, London, UK.

Swingle, W.T. 1928. Metaxenia in the date palm: possibly a hormone action by the embryo or endosperm. Journal of Heredity 19: 257-268.

Trueman, S.J.; Turnbull, C.G.N. 1994. Effects of cross-pollination and flower removal on fruit set in Macadamia. Annals of Botany 73: 23-32.

Valadi, H.; Ekström, K.; Bossios, A.; Sjöstrand, M.; Lee, J.J.; Lötvall, J.O. 2007. Exosome-mediated transfer of mRNAs and microRNAs is a novel mechanism of genetic exchange between cells. Nature Cell Biology 9: 654-659.

Voinnet, O. 2009. Origin, biogenesis, and activity of plant microRNAs. Cell 136: 669-687.

Wallace, H.M.; Lee, L.S. 1999. Pollen source, fruit set and xenia in mandarins. Journal of Horticultural Science and Biotechnology 74: 82-86.

Weingartner, U.; Kaeser, O.; Long, M.; Stamp, P. 2002. Combining cytoplasmic male sterility and xenia increases grain yield of maize hybrids. Crop Science 42: 1848-1856. 